\title{
THERMO-CATALYTIC DEGRADATION OF POLYSTYRENE OVER $\alpha-\mathrm{Fe}_{2} \mathrm{O}_{3}$
}

\author{
Kateřina KLEMENCOVÁ, Barbora GRYCOVÁ, Amer INAYAT, Pavel LEŠTINSKÝ \\ VSB - Technical University of Ostrava, Ostrava, Czech Republic, EU, \\ katerina.klemencova@vsb.cz
}

https://doi.org/10.37904/nanocon.2020.3719

\begin{abstract}
Polystyrene (PS) is an important plastic material, which is widely used in packaging, home, construction, electrical appliances, medical equipment etc. The widespread use of PS generates large amounts of PS wastes, which is due to poor recycling rates globally end up in landfills as well as in the oceans. The increasing amounts of wastes polystyrene and other wastes plastics thus represent a serious threat to the environment, and also to human and animal health. Chemical recycling is an environmentally friendly approach that can be applied for the recycling of plastics. For chemical recycling, thermal or thermo-catalytic pyrolysis/degradation can be used. During the degradation process, polymeric materials are converted into their monomers or other valuable compounds. This paper deals with the synthesis of $\alpha-\mathrm{Fe}_{2} \mathrm{O}_{3}$ nanoparticles and their use as catalyst in thermo-catalytic degradation of PS in a semi-batch reactor. The aim was to study the influence of synthesis parameters on the catalytic properties of $\alpha-\mathrm{Fe}_{2} \mathrm{O}_{3}$ in $\mathrm{PS}$ degradation. The $\alpha-\mathrm{Fe}_{2} \mathrm{O}_{3}$ catalyst samples were prepared by the chemical precipitation method using $\mathrm{FeCl}_{3} \cdot 6 \mathrm{H}_{2} \mathrm{O}$ as a precursor salt and $\mathrm{NaOH}$ as precipitating agent and by calcining the precipitates at different temperatures. All catalyst samples prepared were characterized by $\mathrm{XRD}$ and physisorption of nitrogen. It is shown that by increasing the calcination temperature of precipitates, pure $\alpha-\mathrm{Fe}_{2} \mathrm{O}_{3}$ (hematite phase) can be obtained. Furthermore, it is demonstrated that PS degradation using pure hematite as catalyst in comparison with mixed phase or non-catalytic degradation gives higher yields of oil and styrene monomer.
\end{abstract}

Keywords: Degradation, chemical recycling, polystyrene, catalyst, pyrolysis

\section{INTRODUCTION}

Nowadays, plastics are an integral part of everyday life. Due to their widespread use in modern society, they have become irreplaceable. In recent years, the amount of produced plastics has been continuously increasing due to the wide possibilities of their use in different sectors. The largest amount of plastics is produced for the packaging industry, which amounts to be approximately $40 \%$. Among various types of plastics, polystyrene (PS) is one of the most important and versatile polymeric material that is used in numerous applications which include packaging, construction, medical equipment etc. The continuously increasing demand for plastics as well as poor recycling rate has caused the accumulation of landfilled plastic waste, which contributes to the environmental problem.

Recycling is one of the possibilities to reduce the amount of produced (virgin) plastics and the associated negative impact on the environment. There are four main categories of plastic recycling, namely primary, secondary, tertiary and quaternary recycling. In recent years, the tertiary recycling which is also known as chemical or feedstock recycling has attracted much attention. This is because it represents a potential effective way of processing waste plastics efficiently from ecological and economic point of view..

In chemical recycling, the waste polymeric materials are converted back to their original monomers or oil /hydrocarbon components which can be reused for the production of pure (virgin quality) polymers or new polymers respectively. Chemical recycling can be realized by thermal or thermo-catalytic 
degradation/pyrolysis of waste polymeric materials. In comparison with thermal degradation, thermo-catalytic degradation offers the possibility of reducing the process temperature and improving the selectivity towards desired compounds. Among various thermoplastics, PS has a unique property to be fully recycled. Therefore, PS wastes are good candidates for the chemical recycling.

In literature, thermo-catalytic degradation of PS has been widely studied. In these studies, the use of solid acids and bases as catalysts has been extensively reported. Ukei et al 2000 concluded that solid bases are effective catalysts for the thermochemical conversion of PS into styrene monomer (SM). Furthermore, it has also been reported that some transition metal oxides have basic sites on their surfaces and therefore can be alternative catalytic materials for converting PS into oil with high fraction of SM. In this regard, $\alpha-\mathrm{Fe}_{2} \mathrm{O}_{3}$ nanoparticles can be attractive catalytic material for PS degradation, which exhibit remarkable structural properties that can be beneficial in the decomposition of PS into SM at low reaction temperature of about $400{ }^{\circ} \mathrm{C}$. Therefore, it is the aim of the present work to synthesis $\alpha-\mathrm{Fe}_{2} \mathrm{O}_{3}$ nanoparticles using different synthesis parameters and test the resulting materials in thermo-catalytic degradation of PS. For this purpose, as a first step, $\alpha-\mathrm{Fe}_{2} \mathrm{O}_{3}$ nanoparticles were prepared by using the chemical precipitation method followed by calcination at different temperatures. As a second step, the influence of calcination temperature on the structural, textural and catalytic properties of synthesized $\alpha-\mathrm{Fe}_{2} \mathrm{O}_{3}$ materials was studied.

\section{MATERIALS AND METHODS}

\subsection{Feedstock and catalyst}

Granular PS (purchased from Sigma Aldrich) with an average diameter of 3-4 mm and an average molecular weight of $192000 \mathrm{~g} \cdot \mathrm{mol}^{-1}$ was used as feedstock. For the catalytic degradation of $\mathrm{PS}, \alpha-\mathrm{Fe}_{2} \mathrm{O}_{3}$ nanoparticles synthesized in house were used as catalyst.

The $\alpha-\mathrm{Fe}_{2} \mathrm{O}_{3}$ catalyst samples were synthesized by the chemical precipitation method using $\mathrm{FeCl}_{3} \cdot 6 \mathrm{H}_{2} \mathrm{O}$ as a precursor salt. For the synthesis, $4 \mathrm{~g} \mathrm{FeCl}_{3} .6 \mathrm{H}_{2} \mathrm{O}$ was dissolved in $100 \mathrm{ml}$ of distilled water. The resulting solution was stirred and heated to $70{ }^{\circ} \mathrm{C}$ for 30 minutes. During this time, the $\mathrm{pH}$ of the solution was adjusted to 11 using 0.4 Molar solution of $\mathrm{NaOH}$. The precipitate obtained was filtered and washed extensively with distilled water until neutrality $(\mathrm{pH} \sim 7)$ as indicated by paper indicator. Afterwards, the precipitate was dried in a drying furnace at $70{ }^{\circ} \mathrm{C}$ for 12 hours. Finally, the dried $\alpha-\mathrm{Fe}_{2} \mathrm{O}_{3}$ precipitates were calcined at three different temperatures i.e. 250,400 and $500{ }^{\circ} \mathrm{C}$ to obtain three catalyst samples, namely $\alpha-\mathrm{Fe}_{2} \mathrm{O}_{3}-250, \alpha-\mathrm{Fe}_{2} \mathrm{O}_{3}-400$ and $\alpha-\mathrm{Fe}_{2} \mathrm{O}_{3}-500$ respectively. All samples were characterized by $\mathrm{X}$-ray powder diffraction (XRD) on a Rigaku SmartLab diffractometer (Rigaku, Japan) with detector D/teX Ultra 250. The source of X-ray irradiation was Co tube (CoKa, $\lambda 1=0.178892 \mathrm{~nm}, \lambda 2=0.179278 \mathrm{~nm}$ ) operated at $40 \mathrm{kV}$ and $40 \mathrm{~mA}$. The textural properties of the samples were determined by physisorption of nitrogen using Micrometrics 3Flex analyzer. For the catalytic experiments, all catalyst samples were pelletized to give a pellet size in the range $0.63-1 \mathrm{~mm}$.

\subsection{Thermal and thermo-catalytic degradation}

Both thermal and thermo-catalytic degradation of PS were carried out in a semi-batch reactor setup under continues nitrogen gas flow at a flowrate of $50 \mathrm{ml} \cdot \mathrm{min}^{-1}$. The schematic diagram of the reactor setup is shown in Figure. 1. All experiments were performed at $400^{\circ} \mathrm{C}$ using a heating rate of $10^{\circ} \mathrm{C} / \mathrm{min}$ and a dwelling time of 1 hour. The operating conditions used in the present work were optimized in our previous study. For all experiments, $4 \mathrm{~g}$ of PS was used that was placed between two layers of quartz wool in a quartz glass reactor tube with a length of $250 \mathrm{~mm}$ and internal diameter of $17 \mathrm{~mm}$. For catalytic experiments, $0.4 \mathrm{~g}$ of catalyst pellets, packed between two quartz wool layers, were placed after the PS bed in the nitrogen flow direction. The reactor was heated using a cylindrical heating jacket which was equipped with a temperature controller. 


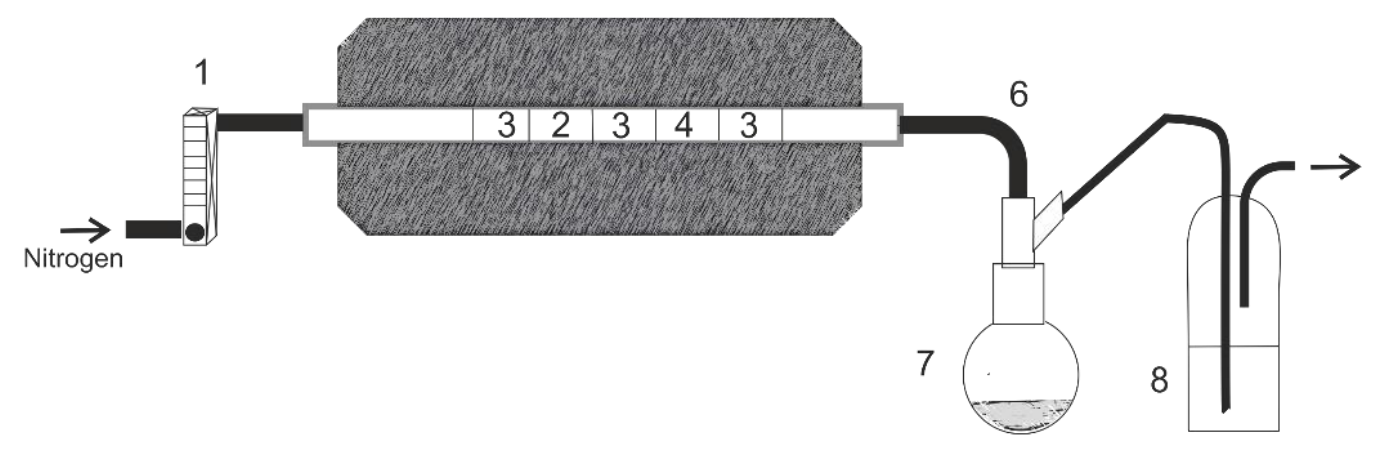

Figure 1 Schematic diagram of semi-batch reactor setup: (1) Flowmeter, (2) Polystyrene, (3) Quartz wool, (4) Catalyst, (5) Electrical heating zone, (6) Air cooling, (7) Round bottom flask with condensate, (8) Washing bottle

\subsection{Product analysis}

For each experiment, two oil (condensate) fractions were obtained. The first fraction was collected in a glass flask by condensing the pyrolysis vapors through air cooling, while the second fraction was condensed inside the reactor tube within the quartz wool. In order to extract the second fraction, the quartz wool loaded with oil was soaked and washed with acetone and the oil was obtained by subsequent evaporation of acetone. The amount of both fractions was determined gravimetrically, and the overall oil yield was determined as the sum of both fractions. The amount of carbon deposited on the spent catalysts was determined using RC612 Multiphase Carbon and Water Analyzer (LECO Instruments). The gas yield was obtained by subtracting the mass of oil and carbon from the mass of feedstock used. The analyses of both oil fractions were performed using gas chromatography. For this purpose, a YL 6100 GC equipped with a HP-5 column and a flame ionization detector was used.

\section{RESULTS AND DISCUSSION}

\subsection{Characterization of catalyst}

The XRD patterns obtained for all three catalysts calcined at three different temperatures are shown in Figure 2. The samples calcined at 400 and $500{ }^{\circ} \mathrm{C}$ exhibited pure hematite phase, whereas the one calcined at $250{ }^{\circ} \mathrm{C}$ showed a mixture of goethite and hematite phases. Moreover, the sample calcined at $500{ }^{\circ} \mathrm{C}$ i.e. $\alpha-\mathrm{Fe}_{2} \mathrm{O}_{3}-500$ showed enhanced crystallinity as compare to the other samples. The textural properties of the catalysts as obtained from the nitrogen adsorption are summarized in Table 1. The results show that with increasing calcination temperature the BET surface area decreased, whereas the pore size increased.

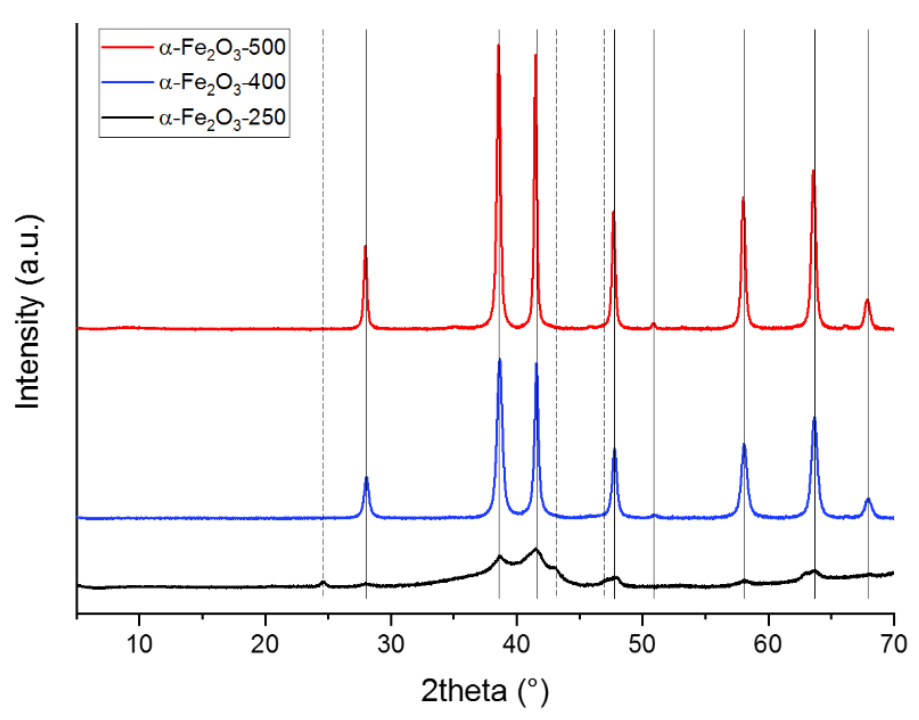

Figure 2 X-ray diffraction patterns of catalyst samples with reference lines indicating Hematite (solid lines) and Goethite (dotted lines) reflexes 
Table 1 Textural properties of synthesized catalyst samples

\begin{tabular}{cccc}
\hline Catalyst & $\begin{array}{c}\mathbf{S}_{\mathrm{BET}} \\
\left(\mathbf{m}^{2} \mathbf{g}^{-1}\right)\end{array}$ & $\begin{array}{c}\mathbf{V}_{\text {net }} \\
\left(\mathbf{c m}^{3}(\mathbf{S T P}) \cdot \mathbf{g}^{-1}\right)\end{array}$ & $\begin{array}{c}\mathbf{d}_{\text {pore }} \\
(\mathbf{n m})\end{array}$ \\
\hline$\alpha-\mathrm{Fe}_{2} \mathrm{O}_{3}-250$ & 165 & 211 & 4.5 \\
$\alpha-\mathrm{Fe}_{2} \mathrm{O}_{3}-400$ & 66 & 212 & 14.4 \\
$\alpha-\mathrm{Fe}_{2} \mathrm{O}_{3}-500$ & 36 & 197 & 29.3 \\
\hline
\end{tabular}

\subsection{Product analysis}

The pyrolytic products from thermal and thermo-catalytic degradation of PS are shown in Figure 3. For all experiments main products obtained were oil and gas. No char was produced in any of the experiments. Only a small amount of carbon was observed on the surface of spent catalysts. The amount of deposited carbon was found to be less than $0.5 \mathrm{wt}$. \%. The main components of oil produced were SM and oligomers (di-and trimers). In addition to SM and oligomers, some minor compounds including benzene, toluene, ethyl benzene and alpha-methylstyrene (not shown here) were also produced. The total amount of all minor compound was less than 5 wt. \%.

From the results as depicted in Figure 3, a trend of higher oil and SM yields with increasing calcination temperature can be observed. This can be attributed to the enhanced crystallinity (at higher calcination temperature) that may lead to higher basicity of the sample. It has been reported that base catalysts are effective catalysts for PS degradation, and as some transition metal oxides have basic sites on their surfaces, they can be potential catalytic material for this reaction in order to improve the selectivity for oil as well as styrene monomer.

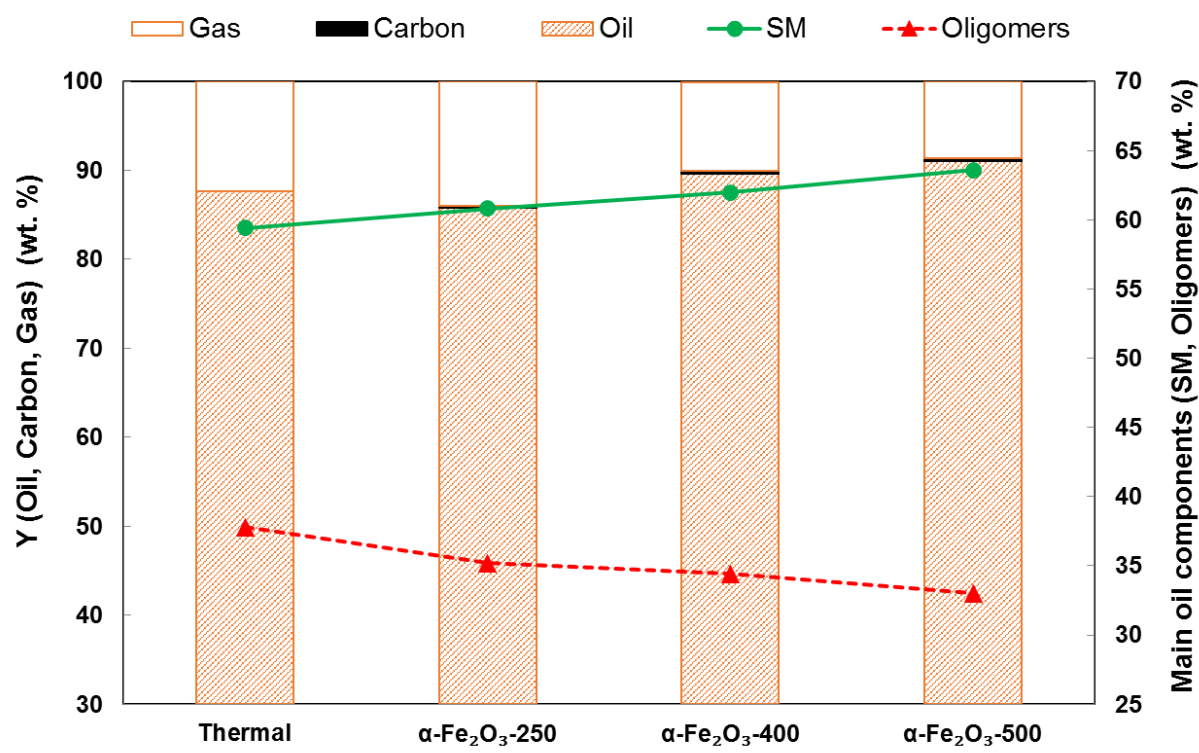

Figure 3 Pyrolytic products obtained from thermal and thermo-catalytic degradation of PS

Table 2 Composition of oligomers produced

\begin{tabular}{cccc}
\hline Catalyst & $\begin{array}{c}\text { Total oligomers } \\
\text { (wt. \%) }\end{array}$ & $\begin{array}{c}\text { Dimers } \\
\text { (wt. \%) }\end{array}$ & $\begin{array}{c}\text { Trimers } \\
\text { (wt. \%) }\end{array}$ \\
\hline Thermal & 37.8 & 22.6 & 15.2 \\
$\alpha-\mathrm{Fe}_{2} \mathrm{O}_{3}-250$ & 35.2 & 16.2 & 19.0 \\
$\mathrm{\alpha}-\mathrm{Fe}_{2} \mathrm{O}_{3}-400$ & 34.4 & 19.6 & 14.8 \\
$\mathrm{\alpha}-\mathrm{Fe}_{2} \mathrm{O}_{3}-500$ & 33.0 & 14.9 & 18.1 \\
\hline
\end{tabular}




\section{CONCLUSION}

Thermo-catalytic degradation of PS was studied over $\alpha-\mathrm{Fe}_{2} \mathrm{O}_{3}$ nanoparticle used as catalyst. The catalyst samples were synthesized by precipitation followed by calcination at 250,400 and $500{ }^{\circ} \mathrm{C}$. Different calcination temperatures led to different phases and textual properties of the samples. From XRD analyses it was shown that pure $\alpha-\mathrm{Fe}_{2} \mathrm{O}_{3}$ phase could be achieved at higher calcination temperature. The results of thermo-catalytic degradation of PS over $\alpha-\mathrm{Fe}_{2} \mathrm{O}_{3}$ showed that all three catalysts produced different amounts of oil, gas and SM. A trend of higher oil and SM yield was observed with increasing the calcination temperature. The present study shows that $\alpha-\mathrm{Fe}_{2} \mathrm{O}_{3}$ nanoparticles can be interesting catalytic materials for thermo-catalytic degradation of PS. However, it is important to tune the properties (through synthesis parameters) of such materials in order to improve the selectivity for target products, as different phases and textural properties will lead to different product spectra.

\section{ACKNOWLEDGEMENTS}

This paper has been elaborated in the framework of the projects "Institute of Environmental Technology - Excellent Research" (CZ.02.1.01/0.0/0.0/16_019/0000853) and "Development of the UniCRE Centre" (LO1606). Experimental results were accomplished by using Large Research Infrastructures ENREGAT (LM2018098) and CATPRO (LM2015039) which were financially supported by the Ministry of Education, Youth and Sports of the Czech Republic.

\section{REFERENCES}

[1] PARK, K. B., JEONG, Y.S., GUZELCIFTCI, B., KIM, J.S. Two-stage pyrolysis of polystyrene: Pyrolysis oil as a source of fuels or benzene, toluene, ethylbenzene, and xylenes. Applied Energy. 2020, vol. 259.

[2] SHARUDDIN, S.C.A., ABNISA, F., DAUD, W.M.A.W., AROUA, M.K. A review on pyrolysis of plastic waste. Energy Conversion and Management. 2016, vol. 115, pp. 308-326.

[3] HAMAD, K., KASEEM, M., DERI, F. Recycling of waste from polymer materials: An overview of the recent works. Polymer degradation and stability. 2013, vol. 98, pp. 2801-2812.

[4] OKAN, D.K., VINU, R. Resource recovery via catalytic fast pyrolysis of polystyrene using zeolites. Journal of analytical and applied pyrolysis. 2015, vol. 113, pp. 349-359.

[5] WANG, J., JIANG, J., SUN, Y., ZHONG, Z., WANG, X., XIA, H., LIU, G., PANG, S., WANG, K., LI, M., XU, J., RUAN, R., RAGAUSKAS, A.J. Recycling benzene and ethylbenzene from in situ catalytic fast pyrolysis of plastic waste. Energy Conversion and Management. 2019, vol.200.

[6] UKEI, H., HIROSE, T., HORIKAWA. S. Catalytic degradation of polystyrene into styrene and a design of recyclable polystyrene with dispersed catalysts. Catalysis today. 2000, vol. 62, pp. 67-75.

[7] GU, R., LEE, O., SALEHZADAH, Y. An investigation into Polystyrene Recycling at UBC [online]. [viewed 2020-930]. Available from: https://open.library.ubc.ca/clRcle/collections/undergraduateresearch/18861/items/1.0108209

[8] OJHA, D.K., VINU, R. Resource recovery via catalytic fast pyrolysis of polystyrene using zeolites. Journal of Analytical and Applied Pyrolysis. 2015, vol. 113, pp. 349-359.

[9] KIJENSKI, J., KACZOREK, T. Catalytic degradation of polystyrene. Polimery. 2005.

[10] CONNEL, G., DUMESIC, J.A. The generation of Brønsted and Lewis acid sites on the surface of silica by addition of dopant cations. Journal of Catalysis. 1987, vol. 105, pp.285-298.

[11] VALÁŠKOVÁ, M., CHLEBÍKOVÁ, L., LEŠTINSKÝ, P. $\alpha$-Fe2O3 nanoparticles/vermiculite composites prepared for catalytic decomposition of polystyrene. Materialstoday Proceeding. 2020.

[12] INAYAT, A., KLEMENCOVÁ, K., GRYCOVÁ, B., SOKOLOVÁ, B., LEŠTINSKÝ, P. Thermo-catalytic pyrolysis of polystyrene in batch and semi-batch reactors: A comparative study. Waste Management \& Research. 2020. 